\title{
Article \\ An Attempt to Predict Changes in Heart Rate Variability in the Training Intensification Process among Cyclists
}

\author{
Paulina Hebisz *, Rafał Hebisz and Agnieszka Jastrzębska \\ Department of Physiology and Biochemistry, University School of Physical Education in Wrocław, \\ 35 I.J. Paderewski Avenue, 51-612 Wrocław, Poland; rafalhebisz@poczta.fm (R.H.); \\ agnieszka.jastrzebska@awf.wroc.pl (A.J.) \\ * Correspondence: paulinahebisz@interia.pl
}

Citation: Hebisz, P.; Hebisz, R.; Jastrzębska, A. An Attempt to Predict Changes in Heart Rate Variability in the Training Intensification Process among Cyclists. Int. J. Environ. Res. Public Health 2021, 18, 7636. https:// doi.org/10.3390/ijerph18147636

Academic Editor: Paul B. Tchounwou

Received: 16 June 2021

Accepted: 14 July 2021

Published: 18 July 2021

Publisher's Note: MDPI stays neutral with regard to jurisdictional claims in published maps and institutional affiliations.

Copyright: (c) 2021 by the authors. Licensee MDPI, Basel, Switzerland. This article is an open access article distributed under the terms and conditions of the Creative Commons Attribution (CC BY) license (https:// creativecommons.org/licenses/by/ $4.0 /)$.

\begin{abstract}
Individual changes in resting heart rate variability (HRV) parameters were assessed in seven Polish cyclists during a training process consisting of: a six-week period (P1) of predominantly low- and moderate-intensity training (L-MIT) and a six-week period (P2) where the proportion of high-intensity interval training (HIT) increased. Daily recorded HRV parameters included highfrequency spectral power (HF), square root of the mean squared difference between successive normal-to-normal RR intervals (RMSSD), and standard deviation of normal-to-normal RR intervals (SDNN). In each training microcycle, the average values of $\mathrm{HF}_{\mathrm{av}}, \mathrm{RMSSD}_{\mathrm{av}}$, and $\mathrm{SDNN}_{\mathrm{av}}$ were calculated individually for each participant. In three cyclists, HF was higher in P2 compared to P1, whereas in one cyclist, HF was higher in P1 than in P2. Each of these four cyclists presented an individual correlation between the average daily duration HIT effort in training microcycles ( $\left.\mathrm{HIT}_{\mathrm{av}}\right)$ and $\mathrm{HF}_{\mathrm{av}}$. Cyclists with low baseline values of HRV parameters showed increased activity of the parasympathetic nervous system, while in the cyclist with high baseline values of HRV parameters, an opposite change was observed. In conclusion, changes in resting HRV parameters between period P1 and P2 can be individualised. In the investigated group, it was possible to predict how HRV would change as a result of training intensification on the basis of HRV baseline values.
\end{abstract}

Keywords: heart rate variability; high-intensity interval training; cardiorespiratory fitness

\section{Introduction}

Training intensification comprises changes in the intensity, duration, and frequency of training sessions in a training process lasting from several weeks to even several months [1] According to Solli et al. [2], training intensification is a classic periodization model for endurance athletes. On the other hand, Smith [3] indicates that the training periodization is not only planning the distribution of training loads, but also planning the frequency of races, tests assessing the level of athletes' efficiency, and planning regeneration periods. Among endurance athletes, low- and moderate-intensity training (L-MIT) accounts for $80 \%$ of total training load, and $20 \%$ is high-intensity interval training (HIT) [1]. Training intensification consists in reducing the duration and frequency of L-MIT training sessions and increasing the duration and frequency of HIT training [1].

Literature distinguishes two variations of interval training, one involving exercise performed at maximal intensity (sprint interval training) with the other at high intensity above the lactate/ventilatory threshold or with an intensity at 95-125\% maximal aerobic power [4-6]. The interval training protocol includes multiple repetitions of exercise, often lasting from a few seconds to several minutes, separated by recovery periods of varying duration [4-7]. However, the effects of training intensification on cardiorespiratory and performance changes are not clear.

According to some studies, training intensification is a process that positively influences the development of cardiorespiratory efficiency [4,8], as measured by the level of maximal oxygen uptake $\left(\mathrm{VO}_{2} \max \right)$ [9]. On the other hand, studies on cross-country 
skiers by Evertsen et al. [10] did not show any significant differences in physiological and performance changes between moderate-intensity and high-intensity training groups. Gaskill et al. [11], as a result of a two-year research project, describe athletes achieving improvements in physiological test results and race performances by implementing traditional training loads, with a predominance of L-MIT training, and a second group of athletes with no performance improvement resulting from a traditional approach. However, the application of training intensification in this group achieved the expected results. The above reports indicate that the issue of training intensification should be approached individually, as it is beneficial only for some athletes.

The effects of training intensification are assessed on the basis of physiological and performance changes $[1,11]$. Up to now, researchers have mainly been focused on adaptive changes to the training process in general, and thus individuals may be missed. The phenomena of individual reactions and adaptive changes dependent on specific training are known facts. Therefore, it seems reasonable to look for factors that could characterize individuals. This will allow one to more accurately predict the development of cardiorespiratory fitness in response to a several-week training intensification programme consisting of L-MIT and HIT efforts.

A popular method to evaluate cardiorespiratory fitness is an analysis of autonomic nervous system activity based on the records of resting [12-14] or restitution [15] sinus heart rate variability (HRV). A measurement of HRV is often used to assess training load [16] and post-exercise fatigue in athletes [17-19]. Moreover, changes in HRV parameters are analysed in relation to the level of aerobic capacity, as measured by the value of maximal oxygen uptake [9]. Ueno et al. [14] and Oliveira et al. [20] observed that obtaining high aerobic capacity was accompanied by an increase in HRV parameters identifying vagus nerve activation. Moreover, Botek et al. [21] found that maintaining high resting highfrequency spectral power (HF), total spectral power (T), and the square root of the mean squared difference between successive values of normal-to-normal RR intervals (RMSSD) in the training process allows for the effective development of aerobic capacity. Høydal [22] and Garber et al. [23] have shown that participants with a high $\mathrm{VO}_{2}$ max level struggle to achieve further improvement in $\mathrm{VO}_{2}$ max through training, as compared to individuals with a low $\mathrm{VO}_{2}$ max level. This raises the question of whether, among athletes with high values of HRV parameters, it will be more difficult to improve them in the training process because, as it has been shown, $\mathrm{VO}_{2}$ max correlates with $\mathrm{HRV}$ parameters [14,20]. Many athletes divide the training process into a period of predominant moderate-intensity efforts and a period of increased high-intensity efforts [2,24]. However, available literature lacks information on whether one can predict resting HRV changes in the training intensification process.

Therefore, the aim of this study was to evaluate individual changes in resting HRV parameters in cyclists during a training process wherein, after a period of predominant L-MIT training, the proportion of HIT training increased. It was assumed that, in cyclists characterised by low (as compared with other observed individuals) baseline resting HF and RMSSD, training intensification would result in relatively large changes in these parameters, while in cyclists with high (as compared with other participants) baseline resting HF and RMSSD, training intensification would result in relatively small changes in these parameters.

\section{Materials and Methods}

\subsection{Participants}

Seven Polish mountain-bike cyclists (four men: S1, S3, S5, S6; and three women: S2, S4, S7) participated in this study. Prior to the experiment, each cyclist had at least three years of training experience and had participated in cycling races at the national level. Based on the maximal oxygen uptake, six cyclists can be rated at aerobic fitness level, while the S3 cyclist, at an elite level, in accordance with the criteria proposed by Figueira et al. [25] and Joyner and Coyle [26]. Table 1 presents the physiological and anthropometric characteristics of the studied cyclists and their experience in practicing cycling. 
Table 1. Individual characteristics of the study participants based on the incremental exercise test, HRV analyses performed before the experiment and competitive status.

\begin{tabular}{|c|c|c|c|c|c|c|c|}
\hline Variables & S1 & S2 & S3 & S4 & S5 & S6 & S7 \\
\hline Age [year] & 21 & 18 & 24 & 17 & 20 & 22 & 20 \\
\hline Body mass [kg] & 75.4 & 55.8 & 73.2 & 49.3 & 62.2 & 70.9 & 54.7 \\
\hline Body height [m] & 1.83 & 1.71 & 1.81 & 1.62 & 1.71 & 1.86 & 1.63 \\
\hline $\mathrm{VO}_{2} \max \left[\mathrm{ml} \cdot \mathrm{min}^{-1} \cdot \mathrm{kg}^{-1}\right]$ & 66.6 & 58.1 & 77.0 & 58.0 & 62.4 & 68.7 & 60.4 \\
\hline $\mathrm{Pmax}_{1}\left[\mathrm{~W} \cdot \mathrm{kg}^{-1}\right]$ & 5.97 & 4.70 & 6.52 & 4.56 & 5.66 & 5.97 & 5.34 \\
\hline $\operatorname{Pmax}_{1}[\mathrm{~W}]$ & 450 & 262 & 477 & 225 & 352 & 423 & 292 \\
\hline $\operatorname{Pmax}_{2}[\mathrm{~W}]$ & 460 & 275 & 465 & 240 & 344 & 418 & 310 \\
\hline $\mathrm{VT} 2{ }_{1}[\mathrm{~W}]$ & 305 & 205 & 320 & 140 & 225 & 305 & 205 \\
\hline $\mathrm{VT} 2_{2}[\mathrm{~W}]$ & 330 & 190 & 335 & 145 & 220 & 305 & 215 \\
\hline $\mathrm{HF}_{\mathrm{b}}\left[\mathrm{ms}^{2}\right]$ & 546 & 689 & 1381 & 3922 & 3597 & 10,746 & 30,865 \\
\hline $\mathrm{LF}_{\mathrm{b}}\left[\mathrm{ms}^{2}\right]$ & 137 & 890 & 3082 & 4060 & 2086 & 2526 & 5881 \\
\hline $\mathrm{RMSSD}_{\mathrm{b}}[\mathrm{ms}]$ & 39 & 53.1 & 86.1 & 119.3 & 111 & 168.3 & 333.4 \\
\hline $\mathrm{SDNN}_{\mathrm{b}}[\mathrm{ms}]$ & 27.9 & 43.2 & 72.3 & 93.1 & 81.1 & 133.7 & 207.7 \\
\hline $\mathrm{RRNN}_{\mathrm{b}}[\mathrm{ms}]$ & 1006 & 1267 & 1537 & 1140 & 1318 & 1197 & 1398 \\
\hline Experience [y] & 7 & 4 & 9 & 3 & 6 & 7 & 5 \\
\hline
\end{tabular}

HRV—heart rate variability; S1—first participant of the study (a man cyclist); S2—second participant of the study (a woman cyclist); S3-third participant of the study (a man cyclist); S4-fourth participant of the study (a woman cyclist); S5—fifth participant of the study (a man cyclist); S6 - sixth participant of the study (a man cyclist); S7—-seventh participant of the study (a woman cyclist); $\mathrm{VO}_{2}$ max-maximal oxygen uptake; $\mathrm{Pmax}_{1}$ - maximal aerobic power measured before period P1; $\mathrm{Pmax}_{2}$ - maximal aerobic power measured before period P2; VT2 $2_{1}$ - power at the second ventilatory threshold measured before period P1; VT2 2 - power at the second ventilatory threshold measured before period $\mathrm{P} 2 ; \mathrm{HF}_{\mathrm{b}}$ - high-frequency spectral power; $\mathrm{LF}_{\mathrm{b}}$-low-frequency spectral power; $\mathrm{RMSSD}_{\mathrm{b}}$ - square root of the mean squared difference between successive normal-to-normal RR intervals; $\mathrm{SDNN}_{\mathrm{b}}$ - standard deviation of normal-to-normal RR intervals; $\mathrm{RRNN}_{\mathrm{b}}$ - mean normal-to-normal RR intervals; ${ }_{\mathrm{b}}$ - each HRV parameter was expressed as the average of measurements performed in the week preceding the commencement of the experiment; Experience-experience in practicing cycling and competitive status presented in years.

The study design was approved by the local Ethics Committee of the University School of Physical Education (Consent number: 39/2019), and all procedures were performed in accordance with the Declaration of Helsinki. Written informed consent was obtained from the participants and their legal guardians after the study details, procedures, risks, and benefits had been explained.

\subsection{Experimental Design}

The experiment was preceded by a 2-week period of weekly training loads reduced to 3 sessions of $45 \mathrm{~min}$ each with an intensity of $70-85 \%$ of the second ventilatory threshold (VT2) power. The investigation consisted in observing the effects of the training process carried out for 12 weeks and was developed on the basis of the classic periodisation model $[2,27]$. The study was divided into 2 periods, each lasting 6 weeks. In the first period (P1), L-MIT trainings predominated. In the second period (P2), the number and duration of L-MIT trainings were reduced (as compared to the last week of P1), while the number and duration of HIT trainings were increased. In a few cases, the periods were shortened by several days as the participants presented with health problems. In the event of an infection, no extension of any period was allowed, owing to commitments to participate in competitions. In each case, data analysis was stopped 10 days before the first race of the competition period. A flowchart showing the course of the experiment is shown in Figure 1. 


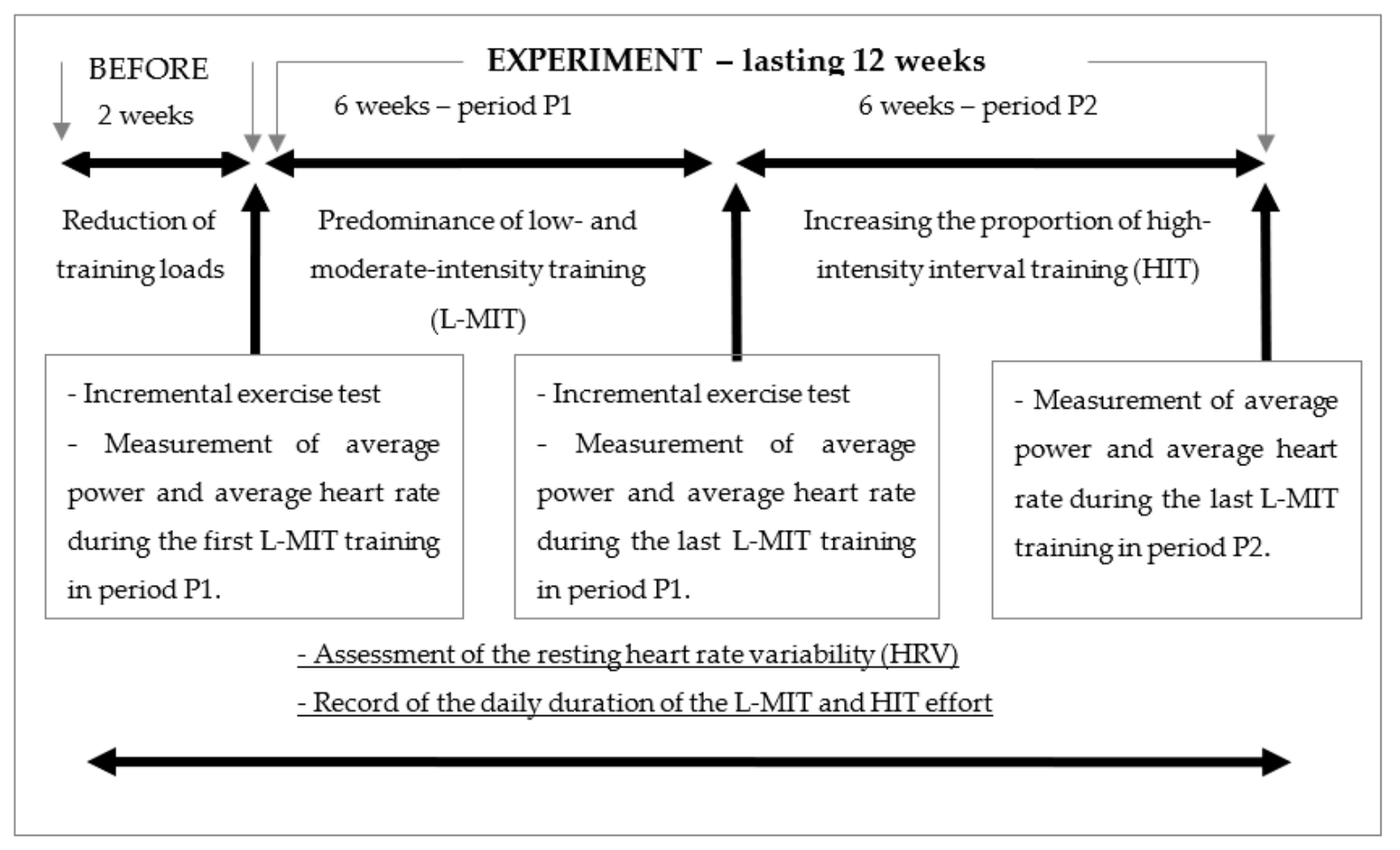

Figure 1. Flowchart of the study design.

In each training period, 4-day training microcycles were implemented. Each microcycle ended with a day of rest (4th day of the microcycle). In P1, the microcycles consisted of the following cycling trainings:

- L-MIT trainings at a level of 70-85\% power measured at VT2 and at $65-75 \%$ of maximal heart rate (HRmax); their duration equalled $2-4 \mathrm{~h}$ (Training 1-T1);

- trainings with exercises requiring high pedalling frequency, at a heart rate of $65-75 \%$ HRmax-repeated efforts with a pedalling frequency increased by 15-25 RPM compared to the individually preferred rhythm (determined on the basis of constantintensity training observations) (Training 2-T2);

- training sessions with repeated exercises of high intensity (above $150 \%$ of maximal aerobic power (Pmax), determined in the incremental exercise test) lasting 15-20 s (Training 3-T3);

- trainings consisting of resistance exercises (e.g., semi-squats) alternated with cycling exercises of high pedalling frequency (increased by 15-25 RPM compared to the individually preferred rhythm), at a heart rate of $65-75 \%$ HRmax (Training 4-T4).

Each microcycle included 2 L-MIT trainings and 1 training selected from among the others mentioned above. In P2, the following cycling trainings were implemented:

- $\quad$ L-MIT trainings at an intensity of 70-85\% power measured at VT2 and at a heart rate of $65-75 \%$ HRmax; their duration equalled 2-3.5 h (Training 5-T5);

- HIT interval trainings involving repeated efforts at $130-160 \%$ Pmax lasting $25-50 \mathrm{~s}$ (Training 6-T6);

- HIT trainings comprised of repeated efforts at 105-120\% Pmax lasting 1-2 min (Training 7-T7);

- HIT trainings consisting of repeated efforts at $90-100 \%$ Pmax lasting 3-6 min (Training 8-T8);

- trainings composed of resistance exercises (e.g., semi-squats) (Training 9-T9).

Each microcycle included 2 HIT trainings selected from among those mentioned above and 1 L-MIT training. In addition, in each period, L-MIT running trainings (at 60-70\% maximum heart rate, determined in the incremental exercise test) and plyometric trainings 
(based on jumping ability exercises) were implemented. In each period, it was possible to extend the training microcycle by 1 day, during which an additional L-MIT training was performed, provided that: (1) the participants evaluated their general feeling as good during the whole microcycle (the evaluated was made on the basis of a conversation with the cyclists and the assessment of the ability to perform the given training loads-when the cyclist reported that he/she could easily perform subsequent training sessions, his wellbeing was assessed as good); (2) the LF/HF ratio determined during the microcycle did not assume values exceeding the individual average value by more than $100 \%$ (such a criterion was adopted based on the observation of the LF/HF index values in the work with cyclists, the results of which are described in this manuscript-such a change usually resulted in a decrease in the ability to perform training sessions); (3) no decrease in power was observed during training compared with previous training microcycles. In each period, it was possible to shorten the training microcycle by 1 day, provided that: (1) the participants evaluated their general feeling as bad during the whole microcycle; (2) the LF/HF ratio determined during the microcycle assumed values exceeding the individual average value by more than $100 \%$; (3) a decrease in power was observed during training compared with previous training microcycles.

During both training periods, it was assumed that the cyclists (performing L-MIT training) should try to keep the heart rate close to that recorded in the first L-MIT training performed during P1 and P2.

Information showing the workload of each cyclist is provided in Table 2.

Table 2. Individual load in cycling training.

\begin{tabular}{|c|c|c|c|c|c|c|c|c|}
\hline \multicolumn{2}{|c|}{ Cycling Training } & S1 & S2 & S3 & S4 & S5 & S6 & S7 \\
\hline \multirow{3}{*}{ T1 } & $\mathrm{t}(\mathrm{min})$ & $120-240$ & $120-210$ & $120-225$ & $120-150$ & $150-230$ & 120-195 & $150-240$ \\
\hline & $\mathrm{P}(\mathrm{W})$ & $215-260$ & $145-175$ & $225-270$ & $100-120$ & $160-190$ & $215-260$ & $145-175$ \\
\hline & Rep & 1 & 1 & 1 & 1 & 1 & 1 & 1 \\
\hline \multirow{4}{*}{ T2 } & $\mathrm{t}(\mathrm{min})$ & $10-20$ & $10-15$ & 10-15 & $5-10$ & $10-15$ & $10-15$ & $10-20$ \\
\hline & RPM & $103-113$ & $101-111$ & 97-107 & $106-116$ & $100-110$ & 98-108 & $106-116$ \\
\hline & $\mathrm{P}(\mathrm{W})$ & $215-260$ & $145-175$ & $225-270$ & $100-120$ & $160-190$ & $215-260$ & $145-175$ \\
\hline & Rep & $2-5$ & 2-4 & $2-5$ & $1-4$ & 2-5 & $2-5$ & $2-5$ \\
\hline \multirow{3}{*}{ T3 } & $\mathrm{t}(\mathrm{s})$ & 15 & 15 & 15 & 15 & 15 & 15 & 15 \\
\hline & $\mathrm{P}(\mathrm{W})$ & $\geq 675$ & $\geq 393$ & $\geq 715$ & $\geq 337$ & $\geq 528$ & $\geq 634$ & $\geq 438$ \\
\hline & Rep & $\overline{1}-4$ & $1-4$ & $\overline{1}-4$ & $\overline{1}-4$ & $\overline{1}-4$ & $\overline{1-4}$ & $\overline{1}-4$ \\
\hline \multirow{4}{*}{ T4 } & $\mathrm{t}(\mathrm{min})$ & 3 & 2 & 3 & 1.5 & 3 & 2 & 3 \\
\hline & RPM & 103-113 & $101-111$ & 97-107 & 106-116 & $100-110$ & 98-108 & 106-116 \\
\hline & $\mathrm{P}(\mathrm{W})$ & $290-320$ & $190-220$ & $305-335$ & $125-155$ & $210-240$ & $290-320$ & $190-220$ \\
\hline & Rep & 3-7 & 3-6 & 3-7 & $2-5$ & 3-7 & 3-7 & $3-7$ \\
\hline \multirow{4}{*}{ T5 } & $\mathrm{t}(\mathrm{min})$ & 120-195 & $120-160$ & 120-195 & 120-135 & 135-195 & 120-180 & $140-210$ \\
\hline & $\mathrm{P}(\mathrm{W})$ & $230-280$ & $130-160$ & $235-285$ & 100-125 & 155-185 & $215-260$ & $150-180$ \\
\hline & Rep & 1 & 1 & 1 & 1 & 1 & 1 & 1 \\
\hline & $\mathrm{t}(\mathrm{s})$ & $40-50$ & $30-40$ & $40-50$ & $25-30$ & $40-50$ & $40-50$ & $40-50$ \\
\hline \multirow[t]{3}{*}{ T6 } & $\mathrm{P}(\mathrm{W})$ & $600-650$ & $380-420$ & $605-655$ & $355-385$ & $450-500$ & $540-590$ & $400-440$ \\
\hline & Rep & 8-16 & 6-12 & 8-20 & 4-10 & $8-16$ & 8-12 & 8-12 \\
\hline & $\mathrm{t}(\mathrm{s})$ & 60-120 & $60-90$ & $60-120$ & $60-80$ & $60-90$ & 60-120 & 60-120 \\
\hline \multirow[t]{3}{*}{ T7 } & $\mathrm{P}(\mathrm{W})$ & $480-520$ & $290-330$ & $485-525$ & $250-290$ & $370-410$ & $440-480$ & $325-365$ \\
\hline & Rep & 5-10 & $3-7$ & 5-8 & $3-6$ & $4-8$ & 3-7 & 5-10 \\
\hline & $\mathrm{t}(\mathrm{min})$ & $4-6$ & $3-4$ & $4-6$ & $3-3.5$ & $4-6$ & $3-5$ & $5-6$ \\
\hline \multirow[t]{2}{*}{ T8 } & $\mathrm{P}(\mathrm{W})$ & $410-450$ & $250-275$ & 415-455 & $215-240$ & $310-345$ & $375-415$ & $280-310$ \\
\hline & Rep & 4-8 & 3-6 & 4-8 & 2-4 & 4-8 & 3-6 & 4-8 \\
\hline
\end{tabular}

S1, S2, etc.-subsequent participants; T1, T2, etc.-subsequent types of cycling training; $t$-duration of training efforts; P-power achieved during training efforts; RPM-pedalling frequency for selected training efforts; Rep-the number of repetitions in one training session.

\subsection{Exercise Test}

Immediately before each training period, an incremental exercise test was performed on a Lode Excalibur Sport cycle ergometer (Lode BV, Groningen, the Netherlands), calibrated before commencement of the study. The test started with a $50 \mathrm{~W}$ load; every $3 \mathrm{~min}$, 
the load was increased by 35 and $50 \mathrm{~W}$ (for women and men, respectively) until refusal due to exhaustion. If the participant was unable to exercise for the entire $3 \mathrm{~min}$ at the last test load, 0.19 and $0.28 \mathrm{~W}$ (for women and men, respectively) was subtracted from the obtained final maximal power for each missed second $[4,28,29]$. In this way, Pmax was calculated.

During the test, respiratory parameters were recorded. The subjects wore a mask connected to a Quark breathing gas analyser (Cosmed, Milan, Italy). The gas analyser was calibrated before the test, via connection with a gas cylinder containing a reference gas mixture consisting of carbon dioxide (5\%), oxygen (16\%), and nitrogen $(79 \%)$. Respiratory parameters were measured breath by breath and then averaged in $30 \mathrm{~s}$ intervals. $\mathrm{VO}_{2}$ max was indicated on the basis of the recorded data, if the subject met at least two of the following three criteria: (1) 90\% of age-predicted maximal heart rate (220—age); (2) respiratory exchange ratio $>1.15$; and (3) lactate concentration $>10 \mathrm{mmol} \cdot \mathrm{l}^{-1}$ [30]. Arterialized capillary blood was drawn 3 min after the test's conclusion to assay lactate concentration by a Lactate Scout (SensLab, Leipzig, Germany). VT2 was indicated with the method of Beaver et al. [31], at the point preceding the second non-linear increase in $\mathrm{VE} \cdot \mathrm{VO}_{2}{ }^{-1}$ or $\mathrm{VE} \cdot \mathrm{VCO}_{2}{ }^{-1}$ equivalent, and the power output at VT2 was then determined.

The previous week, at the beginning of the study and throughout the experiment, the time interval between heartbeats (RR) was recorded with a V800 chest strap and heart rate monitor (Polar Electro Oy, Kempele, Finland). Each recording was performed on a daily basis for $10 \mathrm{~min}$ immediately after waking up, in a supine position. A 5-min segment starting with the 30th second of the recording was analysed. The days on which the athletes had an infection and the first training microcycle from restarting training after the infection were excluded from the analysis. For each recording, the following parameters were calculated: high-frequency spectral power (HF), low-frequency spectral power $(\mathrm{LF})$, total spectral power $(\mathrm{T})$, the square root of the mean squared difference between successive normal-to-normal RR intervals (RMSSD), standard deviation of normal-tonormal RR intervals (SDNN), and the mean normal-to-normal RR intervals (RRNN). The calculations were performed with Kubios HRV Standard software (Kubios Oy, Kuopio, Finland) using the fast Fourier transformation. A low artifact correction threshold was used when performing the analysis.

In each training microcycle, the daily duration of L-MIT effort (performed with a power below VT2) and the daily duration of HIT effort (performed with a power above $90 \%$ Pmax) was recorded. These calculations included only cycling efforts. The remaining efforts were not considered in the data analysis.

For each participant, average power $\left(\mathrm{P}_{\mathrm{av}}\right)$ and average heart rate $\left(\mathrm{HR}_{\mathrm{av}}\right)$ were recorded during 60 min of cycling, immediately after a warm-up, in the L-MIT training implemented in the first microcycle of $\mathrm{P} 1$, in the last microcycle of $\mathrm{P} 1$ and in the last microcycle of $\mathrm{P} 2$. PowerTap P1 power meters (PowerTap, Madison, WI, USA) were used, the reliability and validity of which were determined by Wright et al. [32]. The data analysis was carried out via the flow.polar.com Internet platform, which is used to generate files with a record of heart rate [33,34]. This platform automatically calculated the average values of the parameters for the selected part of the training. The obtained data served to calculate the $\mathrm{P}_{\mathrm{av}} / \mathrm{HR}_{\mathrm{av}}$ ratio.

\subsection{Statistical Calculations and Analyses}

Statistica 13.1 software (StatSoft Inc. Tulsa, OK, USA) was used for statistical calculations. The arithmetic mean and standard deviation values of all analysed HRV parameters, L-MIT effort duration, and HIT effort duration were established for P1 and P2 individually for each cyclist. Student's $t$-test served to individually analyse the probability of difference between P1 and P2 for the mean values of HRV parameters, L-MIT effort duration, and HIT effort duration. A level of probability below 0.05 was considered statistically significant. Based on the arithmetic mean and standard deviations values, Cohen's D values were calculated. 
Average values of all analysed HRV parameters for the previous week at the beginning of the study $\left(\mathrm{HF}_{\mathrm{b}}, \mathrm{LF}_{\mathrm{b}}, \mathrm{RMSSD}_{\mathrm{b}}, \mathrm{SDNN}_{\mathrm{b}}, \mathrm{RRNN}_{\mathrm{b}}\right)$ and average values of all analysed $\mathrm{HRV}$ parameters for each implemented training microcycle during experiment $\left(\mathrm{HF}_{\mathrm{av}}, \mathrm{LF}_{\mathrm{av}}\right.$, $\mathrm{RMSSD}_{\mathrm{av}}, \mathrm{SDNN}_{\mathrm{av}}, \mathrm{RRNN}_{\mathrm{av}}$ ) were calculated individually for each cyclist. Moreover, the average daily L-MIT effort duration (L-MIT $\mathrm{av}$ ) and the average daily HIT effort duration $\left(\mathrm{HIT}_{\mathrm{av}}\right)$ in each training microcycle were determined individually for each cyclist.

The Pearson correlation coefficient between the average values of each analysed HRV parameters in the microcycles $\left(\mathrm{HF}_{\mathrm{av}}, \mathrm{LF}_{\mathrm{av}}, \mathrm{RMSSD}_{\mathrm{av}}, \mathrm{SDNN}_{\mathrm{av}}, \mathrm{RRNN}_{\mathrm{av}}\right)$ and average training loads in the microcycles ( $\mathrm{L}-\mathrm{MIT}_{\mathrm{av}}, \mathrm{HIT}_{\mathrm{av}}$ ) was indicated individually for each participant.

For the whole study group, Pearson correlation coefficient was calculated between the average values of each HRV parameter in the week preceding the experiment commencement $\left(\mathrm{HF}_{\mathrm{b}}, \mathrm{LF}_{\mathrm{b}}, \mathrm{RMSSD}_{\mathrm{b}}, \mathrm{SDNN}_{\mathrm{b}}, \mathrm{RRNN}_{\mathrm{b}}\right)$ and the strength of the individual Pearson correlations between the average values of $\mathrm{HRV}$ parameters in the microcycles $\left(\mathrm{HF}_{\mathrm{av}}, \mathrm{LF}_{\mathrm{av}}\right.$, $\mathrm{RMSSD}_{\mathrm{av}}, \mathrm{SDNN}_{\mathrm{av}}, \mathrm{RRNN}_{\mathrm{av}}$ ) and the average training loads in the microcycles (L-MIT $\mathrm{av}$, $\mathrm{HIT}_{\mathrm{av}}$ ). For each of the Pearson analyses, a probability level below 0.05 was considered statistically significant.

To assess changes in $\mathrm{P}_{\mathrm{av}}$ and $\mathrm{HR}_{\mathrm{av}}$ and $\mathrm{P}_{\mathrm{av}} / \mathrm{HR}_{\mathrm{av}}$ ratio, a one-way analysis of variance with repeated measures and a post-hoc Scheffe test were performed. The probability level below 0.05 was considered statistically significant.

\section{Results}

HF differed between P1 and P2 only in the S1, S2, S3, and S7 cyclists. In the S1, S2, and S3 participants, HF was higher in P2, whereas in S7, HF was higher in P1. Moreover, in the S1 and S2 participants, RMSSD was higher in P2 than in P1. The S7 participant presented RMSSD and SDNN values higher in P1 than in P2. In individual cases, differences in LF, SDNN, and RRNN between P1 and P2 were also observed. In the S4 and S5 cyclists, no difference was noted in any HRV parameter between P1 and P2 (Table 3).

Table 3. Changes in the parameters of sinus heart rate variability and daily training loads in the first (P1) and second (P2) training period. Results presented as individual cases for S1-S7 participants and as the arithmetic mean value for the entire group of cyclists.

\begin{tabular}{|c|c|c|c|c|c|c|c|}
\hline Participants & $\begin{array}{c}\mathrm{HF} \\
{\left[\mathrm{ms}^{2}\right]}\end{array}$ & $\begin{array}{c}\mathrm{LF} \\
{\left[\mathrm{ms}^{2}\right]}\end{array}$ & $\begin{array}{c}\text { RMSSD } \\
{[\mathrm{ms}]}\end{array}$ & $\begin{array}{c}\text { SDNN } \\
{[\mathrm{ms}]}\end{array}$ & $\begin{array}{c}\text { RRNN } \\
{[\mathrm{ms}]}\end{array}$ & $\begin{array}{c}\text { HIT } \\
{[\mathrm{min}]}\end{array}$ & $\begin{array}{l}\text { L-MIT } \\
\text { [min] }\end{array}$ \\
\hline \multicolumn{8}{|c|}{ S1 } \\
\hline P1 & 367.7 & 64.1 & 31.9 & 22.5 & 978.8 & 0.3 & 94.2 \\
\hline$(n=31)$ & \pm 217.8 & \pm 57.1 & \pm 9.8 & \pm 6.7 & \pm 53.0 & \pm 0.9 & \pm 77.7 \\
\hline P2 & 644.1 & 119.3 & 42.3 & 29.8 & 991.1 & 8.0 & 82.0 \\
\hline$(n=30)$ & $\pm 401.0 * *$ & $\pm 71.4^{* *}$ & $\pm 13.9^{* *}$ & $\pm 8.9^{* *}$ & \pm 44.7 & $\pm 13.3^{* *}$ & \pm 58.7 \\
\hline$t$ & -3.36 & -3.34 & -3.37 & -3.62 & -0.98 & -3.24 & 0.69 \\
\hline $\mathrm{D}$ & 0.89 & 0.86 & 0.88 & 0.94 & 0.25 & 1.08 & 0.18 \\
\hline \multicolumn{8}{|c|}{ S2 } \\
\hline P1 & 927.7 & 743.5 & 64.9 & 44.7 & 1315.6 & 0.1 & 81.7 \\
\hline$(n=35)$ & \pm 439.1 & \pm 687.2 & \pm 15.8 & \pm 11.6 & \pm 81.1 & \pm 0.3 & \pm 71.2 \\
\hline P2 & 1184.6 & 795.4 & 76.7 & 51.4 & 1457.6 & 6.0 & 79.2 \\
\hline$(n=43)$ & $\pm 566.5^{*}$ & \pm 544.9 & $\pm 17.6^{* *}$ & \pm 15.6 * & $\pm 108.8^{* *}$ & $\pm 9.1^{* *}$ & \pm 68.0 \\
\hline$t$ & -2.20 & -0.37 & -3.09 & -2.11 & -6.62 & -3.81 & -0.52 \\
\hline $\mathrm{D}$ & 0.51 & 0.08 & 0.71 & 0.49 & 1.50 & 1.26 & 0.04 \\
\hline \multicolumn{8}{|c|}{ S3 } \\
\hline P1 & 1023.8 & 1928.3 & 76.6 & 60.4 & 1588.5 & 0.1 & 95.2 \\
\hline$(n=43)$ & \pm 524.3 & \pm 1048.5 & \pm 16.3 & \pm 13.1 & \pm 75.0 & \pm 0.3 & \pm 82.0 \\
\hline $\mathrm{P} 2$ & 1522.1 & 2177.8 & 81.0 & 64.9 & 1511.4 & 6.1 & 84.8 \\
\hline$(n=40)$ & $\pm 816.5^{* *}$ & \pm 1723.2 & \pm 13.4 & \pm 14.1 & $\pm 89.1^{* *}$ & $\pm 10.1^{* *}$ & \pm 67.2 \\
\hline$t$ & -3.33 & -0.80 & -1.33 & -1.52 & 4.27 & -3.97 & 0.63 \\
\hline $\mathrm{D}$ & 0.74 & 0.18 & 0.30 & 0.33 & 0.94 & 1.15 & 0.14 \\
\hline
\end{tabular}


Table 3. Cont.

\begin{tabular}{|c|c|c|c|c|c|c|c|}
\hline Participants & $\begin{array}{c}\mathrm{HF} \\
{\left[\mathrm{ms}^{2}\right]}\end{array}$ & $\begin{array}{c}\mathrm{LF} \\
{\left[\mathrm{ms}^{2}\right]}\end{array}$ & $\begin{array}{c}\text { RMSSD } \\
\text { [ms] }\end{array}$ & $\begin{array}{c}\text { SDNN } \\
{[\mathrm{ms}]}\end{array}$ & $\begin{array}{c}\text { RRNN } \\
\text { [ms] }\end{array}$ & $\begin{array}{c}\text { HIT } \\
{[\mathrm{min}]}\end{array}$ & $\begin{array}{l}\text { L-MIT } \\
\text { [min] }\end{array}$ \\
\hline \multicolumn{8}{|c|}{ S4 } \\
\hline P1 & 4101.4 & 2272.9 & 106.7 & 81.8 & 1043.6 & 0.6 & 53.9 \\
\hline$(n=36)$ & \pm 1733.2 & \pm 1146.8 & \pm 25.8 & \pm 16.2 & \pm 83.1 & \pm 1.7 & \pm 56.3 \\
\hline P2 & 4476.8 & 2398.5 & 109.3 & 85.7 & 1027.2 & 3.3 & 46.5 \\
\hline$(n=39)$ & \pm 2349.7 & \pm 1111.0 & \pm 25.1 & \pm 15.4 & \pm 72.8 & $\pm 4.8^{* *}$ & \pm 50.0 \\
\hline$t$ & -0.78 & -0.48 & -0.45 & -1.05 & 0.91 & -3.21 & 0.61 \\
\hline $\mathrm{D}$ & 0.18 & 0.11 & 0.10 & 0.25 & 0.21 & 0.83 & 0.14 \\
\hline \multicolumn{8}{|c|}{ S5 } \\
\hline P1 & 4330.1 & 1719.9 & 122.4 & 85.1 & 1347.8 & 0.7 & 95.4 \\
\hline$(n=42)$ & \pm 1140.4 & \pm 789.5 & \pm 14.6 & \pm 9.6 & \pm 108.7 & \pm 2.1 & \pm 82.9 \\
\hline $\mathrm{P} 2$ & 4699.2 & 1997.4 & 127.3 & 88.1 & 1339.7 & 8.51 & 71.1 \\
\hline$(n=35)$ & \pm 1593.9 & \pm 1204.3 & \pm 17.6 & \pm 13.3 & \pm 85.5 & $\pm 12.9^{* *}$ & \pm 60.3 \\
\hline$t$ & -1.17 & -1.20 & -1.33 & -1.11 & 0.35 & -3.85 & 1.44 \\
\hline $\mathrm{D}$ & 0.27 & 0.28 & 0.30 & 0.26 & 0.08 & 1.04 & 0.34 \\
\hline \multicolumn{8}{|c|}{ S6 } \\
\hline P1 & 7568.7 & 4012.3 & 148.1 & 118.4 & 1277.0 & 0.1 & 84.7 \\
\hline$(n=34)$ & \pm 4036.0 & \pm 3715.5 & \pm 40.3 & \pm 32.7 & \pm 106.1 & \pm 0.3 & \pm 78.9 \\
\hline P2 & 6529.8 & 2747.4 & 130.3 & 101.3 & 1295.8 & 3.3 & 78.6 \\
\hline$(n=42)$ & \pm 4667.4 & \pm 2800.9 & \pm 46.9 & $\pm 35.5 *$ & \pm 74.2 & $\pm 6.7^{* *}$ & \pm 67.4 \\
\hline$t$ & 1.01 & 1.67 & 1.73 & 2.13 & -0.90 & -2.88 & 0.36 \\
\hline $\mathrm{D}$ & 0.24 & 0.39 & 0.41 & 0.50 & 0.21 & 0.91 & 0.08 \\
\hline \multicolumn{8}{|c|}{ S7 } \\
\hline P1 & $23,603.9$ & 6291.4 & 317.2 & 193.1 & 1483.3 & 0.6 & 103.1 \\
\hline$(n=43)$ & \pm 5928.9 & \pm 2258.2 & \pm 41.6 & \pm 19.4 & \pm 91.6 & \pm 1.7 & \pm 92.0 \\
\hline P2 & $15,732.1$ & 4639.7 & 264.2 & 161.6 & 1434.6 & 8.7 & 96.7 \\
\hline$(n=35)$ & $\pm 4225.4 * *$ & $\pm 2137.8^{* *}$ & $\pm 40.1^{* *}$ & $\pm 21.4^{* *}$ & \pm 95.2 * & $\pm 16.3^{* *}$ & \pm 77.8 \\
\hline$t$ & 6.60 & 3.29 & 5.69 & 6.82 & 2.29 & -3.26 & 0.33 \\
\hline $\mathrm{D}$ & 1.55 & 0.75 & 1.30 & 1.54 & 0.52 & 0.90 & 0.08 \\
\hline \multicolumn{8}{|c|}{ Mean } \\
\hline P1 & 6403.9 & 2542.7 & 129.5 & 89.7 & 1310.9 & 0.4 & 87.5 \\
\hline$P 1$ & \pm 8471.5 & \pm 2637.1 & \pm 93.6 & \pm 55.8 & \pm 219.7 & \pm 1.3 & \pm 79.1 \\
\hline \multirow{2}{*}{ P2 } & 4773.9 & 2092.2 & 116.9 & 82.2 & 1312.2 & 5.9 & 74.9 \\
\hline & \pm 5352.5 & \pm 2062.3 & \pm 68.8 & \pm 42.3 & \pm 207.2 & \pm 10.7 & \pm 65.3 \\
\hline
\end{tabular}

HF-high-frequency spectral power; LF-low-frequency spectral power; RMSSD—square root of the mean squared difference between successive normal-to-normal RR intervals; SDNN—standard deviation of normal-to-normal RR intervals; RRNN-mean normal-to-normal RR intervals; HIT—-daily duration of high-intensity training; L-MIT—daily duration of low- and moderate-intensity training; S1, S2, etc. - subsequent participants; P1—first training period; P2—second training period; $n$-number of heart rate variability records performed; $t$-Student's $t$-test value; data is presented as mean \pm standard deviation; D-the value of D-Cohen's statistic; Mean-the value of the arithmetic mean \pm standard deviation for the entire group of cyclists; ${ }^{*} p<0.05$, significant difference between the P1 and P2 value; ** $p<0.01$, significant difference between the P1 and P2 value.

The $\mathrm{P}_{\mathrm{av}} / \mathrm{HR}_{\mathrm{av}}$ ratio increased in the last L-MIT training as compared to the first L-MIT training during $\mathrm{P} 1$ by more than $0.10 \mathrm{~W} \cdot \mathrm{BPM}^{-1}$ in the $\mathrm{S} 1, \mathrm{~S} 3, \mathrm{~S} 5$, and $\mathrm{S} 6$ cyclists. The $\mathrm{P}_{\mathrm{av}} / \mathrm{HR}_{\mathrm{av}}$ ratio increased in the last L-MIT training of $\mathrm{P} 2$ as compared to the last L-MIT training of $\mathrm{P} 1$ by more than $0.10 \mathrm{~W} \cdot \mathrm{BPM}^{-1}$ in the S1, S2, S3, and S7 cyclists. The analysis of variance showed statistically significant main effects for the repeated measures $\mathrm{P}_{\mathrm{av}}(7.73$; $p=0.007 ; \eta 2=0.56)$ and $\mathrm{P}_{\mathrm{av}} / \mathrm{HR}_{\mathrm{av}}(\mathrm{F}=10.03 ; p=0.002 ; \eta 2=0.63)($ Table 4$)$.

Table 4. Power and heart rate during the investigated low- and moderate-intensity trainings.

\begin{tabular}{ccccc}
\hline Participants & Variables & First L-MIT in P1 & Last L-MIT in P1 & Last L-MIT in P2 \\
\hline & $\mathrm{P}_{\mathrm{av}}[\mathrm{W}]$ & 212 & 232 & 275 \\
$\mathrm{~S} 1$ & $\mathrm{HR}_{\mathrm{av}}[\mathrm{BPM}]$ & 142 & 141 & 143 \\
& $\mathrm{P}_{\mathrm{av}} / \mathrm{HR}_{\mathrm{av}}\left[\mathrm{W} \cdot \mathrm{BPM}^{-1}\right]$ & 1.49 & 1.65 & 1.92 \\
$\mathrm{P} 2$ & $\mathrm{P}_{\mathrm{av}}[\mathrm{W}]$ & 152 & 155 & 175 \\
& $\mathrm{HR}_{\mathrm{av}}[\mathrm{BPM}]$ & 149 & 146 & 150 \\
\hline
\end{tabular}


Table 4. Cont.

\begin{tabular}{|c|c|c|c|c|}
\hline Participants & Variables & First L-MIT in P1 & Last L-MIT in P1 & Last L-MIT in P2 \\
\hline \multirow{5}{*}{ S3 } & $\mathrm{P}_{\mathrm{av}} / \mathrm{HR}_{\mathrm{av}}\left[\mathrm{W} \cdot \mathrm{BPM}^{-1}\right]$ & 1.02 & 1.06 & 1.17 \\
\hline & $\mathrm{P}_{\mathrm{av}}[\mathrm{W}]$ & 252 & 265 & 284 \\
\hline & $\mathrm{HR}_{\mathrm{av}}[\mathrm{BPM}]$ & 151 & 142 & 142 \\
\hline & $\mathrm{P}_{\mathrm{av}} / \mathrm{HR}_{\mathrm{av}}\left[\mathrm{W} \cdot \mathrm{BPM}^{-1}\right]$ & 1.67 & 1.87 & 2.00 \\
\hline & $\mathrm{P}_{\mathrm{av}}[\mathrm{W}]$ & 153 & 141 & 160 \\
\hline \multirow[t]{3}{*}{ S4 } & $\mathrm{HR}_{\mathrm{av}}[\mathrm{BPM}]$ & 145 & 141 & 152 \\
\hline & $\mathrm{P}_{\mathrm{av}} / \mathrm{HR}_{\mathrm{av}}\left[\mathrm{W} \cdot \mathrm{BPM}^{-1}\right]$ & 1.05 & 1.00 & 1.05 \\
\hline & $\mathrm{P}_{\mathrm{av}}[\mathrm{W}]$ & 208 & 227 & 234 \\
\hline \multirow[t]{3}{*}{ S5 } & $\mathrm{HR}_{\mathrm{av}}[\mathrm{BPM}]$ & 157 & 155 & 155 \\
\hline & $\mathrm{P}_{\mathrm{av}} / \mathrm{HR}_{\mathrm{av}}\left[\mathrm{W} \cdot \mathrm{BPM}^{-1}\right]$ & 1.32 & 1.46 & 1.51 \\
\hline & $\mathrm{P}_{\mathrm{av}}[\mathrm{W}]$ & 237 & 271 & 251 \\
\hline \multirow[t]{3}{*}{ S6 } & $\mathrm{HR}_{\mathrm{av}}[\mathrm{BPM}]$ & 157 & 160 & 152 \\
\hline & $\mathrm{P}_{\mathrm{av}} / \mathrm{HR}_{\mathrm{av}}\left[\mathrm{W} \cdot \mathrm{BPM}^{-1}\right]$ & 1.51 & 1.69 & 1.65 \\
\hline & $\mathrm{P}_{\mathrm{av}}[\mathrm{W}]$ & 160 & 164 & 176 \\
\hline \multirow[t]{2}{*}{ S7 } & $\mathrm{HR}_{\mathrm{av}}[\mathrm{BPM}]$ & 142 & 146 & 141 \\
\hline & $\mathrm{P}_{\mathrm{av}} / \mathrm{HR}_{\mathrm{av}}\left[\mathrm{W} \cdot \mathrm{BPM}^{-1}\right]$ & 1.13 & 1.12 & 1.25 \\
\hline \multirow[t]{3}{*}{ Mean } & $\mathrm{P}_{\mathrm{av}}[\mathrm{W}]$ & $196.3 \pm 41.4$ & $207.9 \pm 53.8$ & $222.1 \pm 51.3$ * \\
\hline & $\mathrm{HR}_{\mathrm{av}}[\mathrm{BPM}]$ & $149.0 \pm 6.4$ & $147.3 \pm 7.4$ & $147.9 \pm 5.7$ \\
\hline & $\mathrm{P}_{\mathrm{av}} / \mathrm{HR}_{\mathrm{av}}\left[\mathrm{W} \cdot \mathrm{BPM}^{-1}\right]$ & $1.31 \pm 0.25$ & $1.41 \pm 0.35$ & $1.51 \pm 0.37$ * \\
\hline
\end{tabular}

L-MIT-low- and moderate-intensity training; P1—first training period; P2—second training period; S1, S2, etc.-subsequent participants; $\mathrm{P}_{\mathrm{av}}$-average power during $60 \mathrm{~min}$ of cycling in the indicated training; $\mathrm{HR}_{\mathrm{av}}$ —average heart rate during 60 min of cycling in the indicated training; Mean — the value of the arithmetic mean \pm standard deviation for the entire group of cyclists; ${ }^{*}-p<0.05$ vs. first L-MIT in P1.

A statistically significant correlation between $\mathrm{HIT}_{\mathrm{av}}$ and $\mathrm{HF}_{\mathrm{av}}$ was observed. The correlation was positive in the S1, S2, and S3 cyclists and negative in the S7 cyclist. Correlations of the required level of probability were detected between $\mathrm{HIT}_{\mathrm{av}}, \mathrm{RMSSD}_{\mathrm{av}}$, and $\mathrm{SDNN}_{\mathrm{av}}$. These correlations were positive in the S1 and S2 cyclists and negative in the S7 cyclist. In the case of S5, a positive correlation of the required level of statistical probability was identified between $\mathrm{HIT}_{\mathrm{av}}$ and $\mathrm{LF}_{\mathrm{av}}$ only. The $\mathrm{S} 4$ and $\mathrm{S} 6$ cyclists did not present correlations of the required level of statistical probability for $\mathrm{HIT}_{\mathrm{av}}$. No athlete demonstrated statistically significant correlations for L-MIT av (Table 5 and Figure 2).

Table 5. Strength of the Pearson correlation between average training loads and average parameters of sinus heart rate variability recorded in the subsequent training microcycles throughout the experiment (totals for the first and second period).

\begin{tabular}{|c|c|c|c|c|c|}
\hline $\begin{array}{l}\text { Participants } \\
\text { Training load }\end{array}$ & $\begin{array}{l}\mathrm{HF}_{\mathrm{av}} \\
{\left[\mathrm{ms}^{2}\right]}\end{array}$ & $\begin{array}{l}\mathbf{L F}_{\mathrm{av}} \\
{\left[\mathrm{ms}^{2}\right]}\end{array}$ & $\begin{array}{l}\text { RMSSD }_{\mathrm{av}} \\
{[\mathrm{ms}]}\end{array}$ & $\begin{array}{l}\mathrm{SDNN}_{\mathrm{av}} \\
{[\mathrm{ms}]}\end{array}$ & $\begin{array}{c}\text { RRNN }_{\text {av }} \\
{[\mathrm{ms}]}\end{array}$ \\
\hline \multicolumn{6}{|c|}{$\mathrm{S} 1(n=16)$} \\
\hline $\mathrm{HIT}_{\mathrm{av}}[\mathrm{min}]$ & 0.73 * & 0.63 * & 0.69 * & 0.68 * & 0.26 \\
\hline \multicolumn{6}{|c|}{$\mathrm{S} 2(n=20)$} \\
\hline $\mathrm{HIT}_{\mathrm{av}}[\mathrm{min}]$ & 0.49 * & 0.05 & 0.49 * & 0.38 & 0.59 * \\
\hline $\mathrm{L}^{-\mathrm{MIT}_{\mathrm{av}}}[\mathrm{min}]$ & -0.11 & $\begin{array}{l}0.11 \\
\text { S3 ( }\end{array}$ & -0.21 & 0.03 & -0.39 \\
\hline $\mathrm{HIT}_{\mathrm{av}}[\mathrm{min}]$ & 0.50 * & 0.33 & 0.31 & 0.33 & -0.42 \\
\hline $\mathrm{L}^{-\mathrm{MIT}_{\mathrm{av}}}[\mathrm{min}]$ & -0.11 & $\begin{array}{l}0.18 \\
\text { S4 ( }\end{array}$ & 0.06 & 0.24 & -0.23 \\
\hline $\mathrm{HIT}_{\mathrm{av}}[\mathrm{min}]$ & -0.14 & -0.07 & -0.07 & -0.10 & -0.18 \\
\hline \multicolumn{6}{|c|}{ S5 $(n=20)$} \\
\hline $\mathrm{HIT}_{\mathrm{av}}[\mathrm{min}]$ & 0.39 & $0.49 *$ & 0.33 & 0.40 & -0.30 \\
\hline $\mathrm{L}^{-\mathrm{MIT}_{\mathrm{av}}}[\mathrm{min}]$ & 0.09 & $\begin{array}{c}-0.18 \\
\text { S6 }\end{array}$ & 0.13 & 0.08 & 0.21 \\
\hline $\mathrm{HIT}_{\mathrm{av}}[\mathrm{min}]$ & -0.13 & -0.44 & -0.27 & -0.36 & 0.14 \\
\hline $\mathrm{L}^{-\mathrm{MIT}_{\mathrm{av}}[\mathrm{min}]}$ & 0.19 & -0.11 & 0.28 & 0.23 & -0.38 \\
\hline
\end{tabular}


Table 5. Cont.

\begin{tabular}{|c|c|c|c|c|c|}
\hline $\begin{array}{l}\text { Participants } \\
\text { Training load }\end{array}$ & $\begin{array}{l}\mathrm{HF}_{\mathrm{av}} \\
{\left[\mathrm{ms}^{2}\right]}\end{array}$ & $\begin{array}{c}\mathrm{LF}_{\mathrm{av}} \\
{\left[\mathrm{ms}^{2}\right]}\end{array}$ & $\begin{array}{l}\text { RMSSD }_{a v} \\
{[\mathrm{~ms}]}\end{array}$ & $\begin{array}{l}\mathrm{SDNN}_{\mathrm{av}} \\
{[\mathrm{ms}]}\end{array}$ & $\begin{array}{c}\mathrm{RRNN}_{\mathrm{av}} \\
{[\mathrm{ms}]}\end{array}$ \\
\hline \multicolumn{6}{|c|}{$\mathrm{S} 7(n=21)$} \\
\hline $\mathrm{HIT}_{\mathrm{av}}[\mathrm{min}]$ & $-0.48 *$ & -0.39 & $-0.47^{*}$ & -0.53 * & -0.27 \\
\hline $\mathrm{L}^{-\mathrm{MIT}_{\mathrm{av}}}[\mathrm{min}]$ & 0.04 & -0.14 & 0.14 & 0.07 & 0.38 \\
\hline
\end{tabular}

HF-high-frequency spectral power; LF-low-frequency spectral power; RMSSD—square root of the mean squared difference between successive normal-to-normal RR intervals; SDNN—standard deviation of normal-to-normal RR intervals; RRNN-mean normal-to-normal RR intervals; S1, S2, etc.—subsequent participants; $n$-number of training microcycles performed; $\mathrm{HIT}_{\mathrm{av}}$ —daily duration of high-intensity training, averaged values for training microcycles; $\mathrm{L}_{-} \mathrm{MIT}_{\mathrm{av}}$ — daily duration of low- and moderate-intensity training, averaged values for training microcycles; $* p<0.05$.
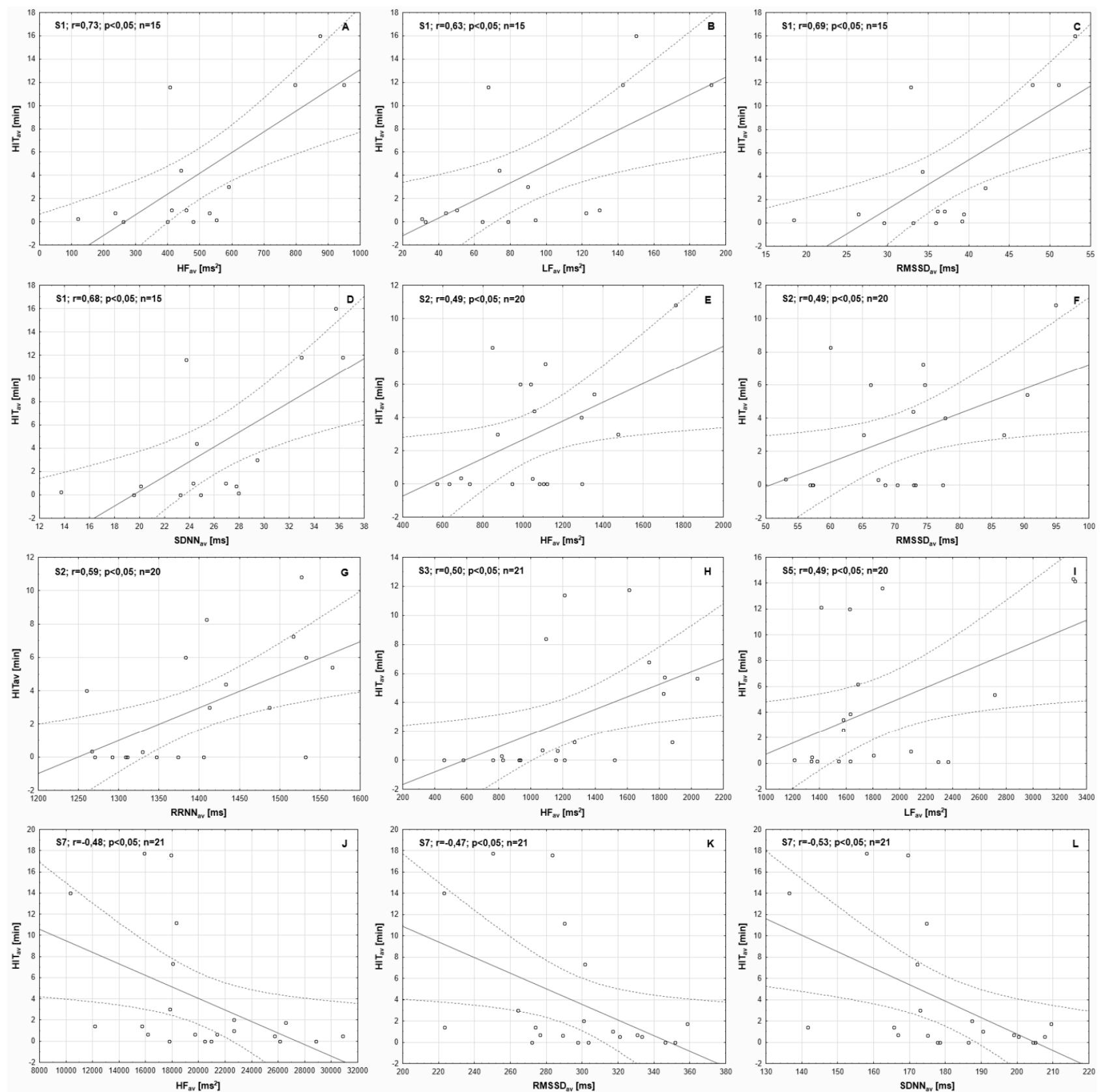

Figure 2. Graphical representation of the statistically significant Pearson's correlations (indicated in Table 5) between daily duration of high-intensity training - averaged values for training microcycles ( $\left.\mathrm{HIT}_{\mathrm{av}}\right)$ and average parameters of sinus heart 
rate variability recorded in the subsequent training microcycles throughout the experiment (totals for the first and second period). S1, S2, etc.-subsequent participants; $r$-correlation coefficient; $p$ - the adopted level of statistical significance; $n$-number of training microcycles performed. ParA—shows the correlation between HIT $_{\mathrm{av}}$ and average value of highfrequency spectral power, recorded in the subsequent training microcycles throughout the experiment (totals for the first and second period) $\left(\mathrm{HF}_{\mathrm{av}}\right)$ - for participant S1; Part $\mathbf{B}$ - shows the correlation between $\mathrm{HIT}_{\mathrm{av}}$ and average value of low-frequency spectral power, recorded in the subsequent training microcycles throughout the experiment (LF $\mathrm{av}_{\text {) }}$-for participant S1; Part C-shows the correlation between $\mathrm{HIT}_{\mathrm{av}}$ and average value of square root of the mean squared difference between successive normal-to-normal RR intervals, recorded in the subsequent training microcycles throughout the experiment $\left(\right.$ RMSSD $\left._{\mathrm{av}}\right)$ - for participant S1; Part D—shows the correlation between $\mathrm{HIT}_{\mathrm{av}}$ and average value of standard deviation of normal-to-normal RR intervals, recorded in the subsequent training microcycles throughout the experiment $\left(\mathrm{SDNN}_{\mathrm{av}}\right)-$ for participant S1; Part E-shows the correlation between $\mathrm{HIT}_{\mathrm{av}}$ and $\mathrm{HF}_{\mathrm{av}}$ - for participant S2; Part F-shows the correlation between HIT $_{\mathrm{av}}$ and $\mathrm{RMSSD}_{\mathrm{av}}$ - for participant S2; Part G-shows the correlation between $\mathrm{HIT}_{\mathrm{av}}$ and average value of mean normal-to-normal RR intervals, recorded in the subsequent training microcycles throughout the experiment $\left(\mathrm{RRNN}_{\mathrm{av}}\right)$-for participant S2; Part H-shows the correlation between $\mathrm{HIT}_{\mathrm{av}}$ and $\mathrm{HF}_{\mathrm{av}}$-for participant S3; Part I-shows the correlation between $\mathrm{HIT}_{\mathrm{av}}$ and $\mathrm{LF}_{\mathrm{av}}$ - for participant S5; Part J-shows the correlation between $\mathrm{HIT}_{\mathrm{av}}$ and HFav -for participant S7; Part K-shows the correlation between $\mathrm{HIT}_{\mathrm{av}}$ and $\mathrm{RMSSD}_{\mathrm{av}}$ — for participant S7; Part L-shows the correlation between $\mathrm{HIT}_{\mathrm{av}}$ and $\mathrm{SDNN}$ av - for participant S7.

It was found that the levels of $\mathrm{HF}_{\mathrm{b}}, \mathrm{LF}_{\mathrm{b}}, \mathrm{RMSSD}_{\mathrm{b}}$, and $\mathrm{SDNN}_{\mathrm{b}}$ measured in the week preceding the experiment were statistically significantly correlated with the strength of the relationship between $\mathrm{HIT}_{\mathrm{av}}$ and $\mathrm{HF}_{\mathrm{av}}, \mathrm{HIT}_{\mathrm{av}}$ and $\mathrm{RMSSD}_{\mathrm{av}}$ and $\mathrm{HIT}_{\mathrm{av}}$ and SDNN (Table 6 and Figure 3).

Table 6. Strength of the Pearson correlation between parameters of sinus heart rate variability recorded in the week preceding the experiment and the strength of the relationship between the training loads and parameters of sinus heart rate variability calculated for the whole experiment period.

\begin{tabular}{cccccc}
\hline Variables & $\begin{array}{c}\mathbf{H F}_{\mathbf{a v}^{-}} \\
\mathbf{H I T}_{\mathbf{a v}}\end{array}$ & $\begin{array}{c}\mathbf{L F}_{\mathbf{a v}} \\
\mathbf{H I T}_{\mathbf{a v}}\end{array}$ & $\begin{array}{c}\text { RMSSD }_{\mathbf{a v}^{-}} \\
\mathbf{H I T}_{\mathbf{a v}}\end{array}$ & $\begin{array}{c}\mathbf{S D N N}_{\mathbf{a v}^{-}} \\
\mathbf{H I T}_{\mathbf{a v}}\end{array}$ & $\begin{array}{c}\text { RRNN }_{\mathbf{a v}^{-}} \\
\mathbf{H I T}_{\mathbf{a v}}\end{array}$ \\
\hline $\mathrm{HF}_{\mathrm{b}}\left[\mathrm{ms}^{2}\right]$ & $-0.83^{*}$ & -0.69 & $-0.82^{*}$ & $-0.82^{*}$ & -0.31 \\
$\mathrm{LF}_{\mathrm{b}}\left[\mathrm{ms}^{2}\right]$ & $-0.87^{*}$ & -0.64 & $-0.87^{*}$ & $-0.83 *$ & -0.67 \\
$\mathrm{RMSSD}_{\mathrm{b}}[\mathrm{ms}]$ & $-0.89^{*}$ & -0.72 & $-0.89^{*}$ & $-0.87^{*}$ & -0.42 \\
$\mathrm{SDNN}_{\mathrm{b}}[\mathrm{ms}]$ & $-0.92^{*}$ & $-0.78^{*}$ & $-0.95^{*}$ & $-0.93 *$ & -0.44 \\
$\mathrm{RRNN}_{\mathrm{b}}[\mathrm{ms}]$ & -0.15 & -0.14 & -0.25 & -0.21 & -0.57 \\
\hline
\end{tabular}

$\mathrm{HF}_{\mathrm{av}}-\mathrm{HIT}_{\mathrm{av}}$-Pearson correlation between the average value of high-frequency spectral power and average high-intensity load in the training microcycles; $\mathrm{LF}_{\mathrm{av}}-\mathrm{HIT}_{\mathrm{av}}$-Pearson correlation between the average value of low-frequency spectral power and average high-intensity load in the training microcycles; $\mathrm{RMSSD}_{\mathrm{av}}-\mathrm{HIT}_{\mathrm{av}}-$ Pearson correlation between the average value of the square root of the mean squared difference between successive normal-to-normal RR intervals and average high-intensity load in the training microcycles; $\mathrm{SDNN}_{\mathrm{av}}{ }^{-}$ $\mathrm{HIT}_{\mathrm{av}}$-Pearson correlation between the average value of the standard deviation of normal-to-normal RR intervals and average high-intensity load in the training microcycles; $\mathrm{RRNN}_{\mathrm{av}}-\mathrm{HIT}_{\mathrm{av}}$-Pearson correlation between the average value of the normal-to-normal RR intervals and average high-intensity load in the training microcycles; $\mathrm{HF}_{\mathrm{b}}$-high-frequency spectral power; $\mathrm{LF}_{\mathrm{b}}$-low-frequency spectral power; RMSSD - square root of the mean squared difference between successive normal-to-normal RR intervals; $\mathrm{SDNN}_{\mathrm{b}}$ - standard deviation of normal-tonormal RR intervals; $\mathrm{RRNN}_{\mathrm{b}}$ - mean normal-to-normal RR intervals; ${ }_{b}$ - each HRV parameter was expressed as the average of measurements performed in the week preceding the experiment; ${ }^{*} p<0.05$. 

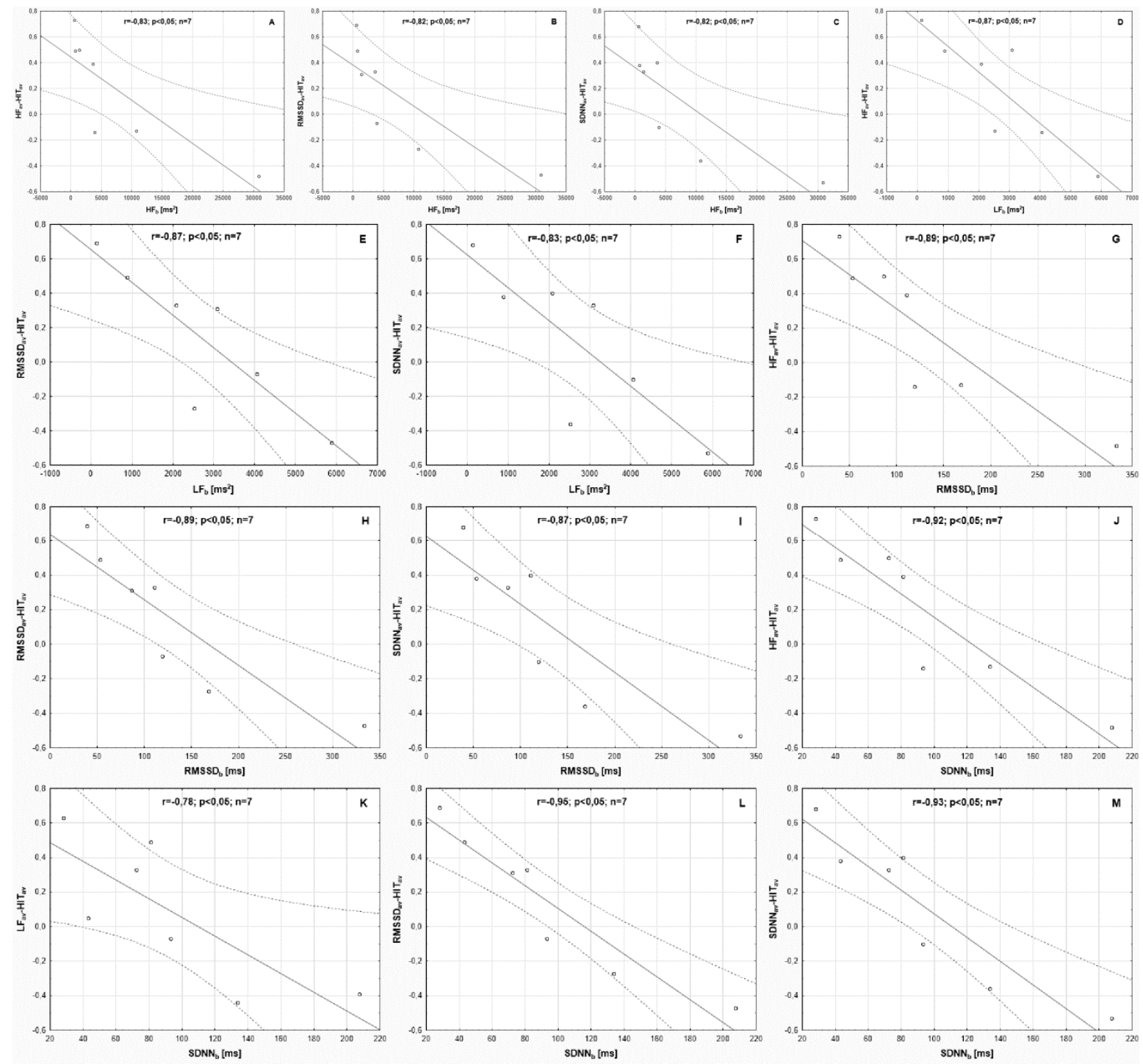

Figure 3. Graphical representation of the statistically significant Pearson's correlations (indicated in Table 6) between the strength of the relationship between the daily duration of high-intensity training-averaged values for training microcycles $\left(\mathrm{HIT}_{\mathrm{av}}\right)$ and parameters of sinus heart rate variability calculated for the whole experiment period and parameters of sinus heart rate variability recorded in the week preceding the experiment. $r$-correlation coefficient; $p$-the adopted level of statistical significance; $n$-number of participants. Part A—shows the correlation between the strength of the relationship between the average value of high-frequency spectral power, recorded in the subsequent training microcycles throughout the experiment (totals for the first and second period) $\left(\mathrm{HF}_{\mathrm{av}}\right)$ and $\mathrm{HIT}_{\mathrm{av}}$, as well as high-frequency spectral power expressed as the average of measurements performed in the week preceding the experiment $\left(\mathrm{HF}_{\mathrm{b}}\right)$; Part $\mathbf{B}$ - shows the correlation between the strength of the relationship between the average value of the square root of the mean squared difference between successive normal-to-normal RR intervals, recorded in the subsequent training microcycles throughout the experiment $\left(\mathrm{RMSSD}_{\mathrm{av}}\right.$ ) and $\mathrm{HIT}_{\mathrm{av}}$, as well as $\mathrm{HF}_{\mathrm{b}}$; Part C—shows the correlation between the strength of the relationship between the average value of the standard deviation of normal-to-normal RR intervals $\left(\mathrm{SDNN}_{\mathrm{av}}\right)$ and $\mathrm{HIT}_{\mathrm{av}}$, as well as $\mathrm{HF}_{\mathrm{b}}$; Part D-shows the correlation between the strength of the relationship between $\mathrm{HF}_{\mathrm{av}}$ and $\mathrm{HIT}_{\mathrm{av}}$, as well as low-frequency spectral power expressed as the average of measurements performed in the week preceding the experiment $\left(\mathrm{LF}_{\mathrm{b}}\right) ; \mathbf{P a r t}_{\mathrm{E}-}$ shows the correlation between the strength of the relationship between RMSSDav and HIT $_{a v}$, as well as LF $_{b}$; Part F-shows the correlation between the strength of the relationship between $\mathrm{SDNN}_{\mathrm{av}}$ and $\mathrm{HIT}_{\mathrm{av}}$, as well as $\mathrm{LF}_{\mathrm{b}}$; Part G-shows the correlation between the strength of the relationship between $\mathrm{HF}_{\mathrm{av}}$ and $\mathrm{HIT}_{\mathrm{av}}$, as well as the square root of the mean squared difference between successive normal-to-normal RR intervals expressed as the average of measurements performed in the 
week preceding the experiment $\left(\mathrm{RMSSD}_{\mathrm{b}}\right)$; Part $\mathrm{H}$-shows the correlation between the strength of the relationship between RMSSD $_{\mathrm{av}}$ and $\mathrm{HIT}_{\mathrm{av}}$, as well as RMSSD ; Part I-shows the correlation between the strength of the relationship between $\mathrm{SDNN}_{\mathrm{av}}$ and $\mathrm{HIT}_{\mathrm{av}}$, as well as RMSSD ; Part J—shows the correlation between the strength of the relationship between $\mathrm{HF}_{\mathrm{av}}$ and $\mathrm{HIT}_{\mathrm{av}}$, as well as standard deviation of normal-to-normal RR intervals expressed as the average of measurements performed in the week preceding the experiment $\left(\mathrm{SDNN}_{\mathrm{b}}\right)$; Part $\mathrm{K}$ - shows the correlation between the strength of the relationship between the average value of low-frequency spectral power, recorded in the subsequent training microcycles throughout the experiment $\left(\mathrm{LF}_{\mathrm{av}}\right)$ and $\mathrm{HIT}_{\mathrm{av}}$, as well as $\mathrm{SDNN}_{\mathrm{b}}$; Part L-shows the correlation between the strength of the relationship between $\mathrm{RMSSD}_{\mathrm{av}}$ and $\mathrm{HIT}_{\mathrm{av}}$, as well as $\mathrm{SDNN}_{\mathrm{b}}$; Part $\mathbf{M}$ - shows the correlation between the strength of the relationship between $\mathrm{SDNN}_{\mathrm{av}}$ and $\mathrm{HIT}_{\mathrm{av}}$, as well as $\mathrm{SDNN}_{\mathrm{b}}$.

\section{Discussion}

In this study, it was shown that, in three cyclists, HF was higher in period P2 than in P1, whilst in the case of one cyclist, HF was higher in period P1 than in P2. In the remaining three cyclists, there were no significant changes in HF. Interestingly, in all four cyclists who had changes in HF between P1 and P2, the Pav/HRav ratio from the last L-MIT training of period P2 was higher than the last L-MIT training of P1. An analysis of the available literature shows that resting heart rate and HRV values are related to aerobic capacity and cardiorespiratory fitness among non-training individuals [13,35]. According to Bellenger et al. [36], an increase in exercise capacity during the training process is associated with an improvement in HRV parameters, such as RMSSD or HF. Sandercock et al. [37] proved in their meta-analysis that a long-term training process based on aerobic effort leads to an increase in resting HF values; Macor et al. [38] reported that competitive cyclists present higher resting HF values than non-training individuals. However, publications describing the impact that intensifying training has on HRV parameters provide inconsistent results. Pichot et al. [39] demonstrated that, over a period of three weeks, when intensive training accounted for $30 \%$ of the total load, the value of HF decreased, although the subject of the study was training that provoked fatigue accumulation. Schneider et al. [40] implied that among well-trained athletes, the natural logarithm of RMSSD did not change after several HIT trainings. Similarly, Daniłowicz-Szymanowicz et al. [41] did not observe changes in HF, RMSSD, or SDNN as a result of a two-month training intensification among trained runners. Raczak et al. [42] compared two training periods of four months each in trained runners. The first period was characterised by a predominance of moderate-intensity training. In the second period, the proportion of high-intensity trainings increased. The RMSSD, SDNN, and LF parameters turned out to be significantly higher in the second period than in the preceding period. The results of the present study indicate that changes in HRV parameters due to intensifying the training process can be individualised among well-trained cyclists.

Lamberts et al. [43] demonstrated that the power output level at submaximal heart rate was a good measure of exercise capacity in cycling. In our study, the above-mentioned HRV parameters improved in P2 among the cyclists S1, S2, and S3. In the same period, the $\mathrm{P}_{\mathrm{av}} / \mathrm{HR}_{\mathrm{av}}$ ratio improved in these cyclists. However, an improvement in the $\mathrm{P}_{\mathrm{av}} / \mathrm{HR}_{\mathrm{av}}$ ratio was also observed in cyclist S7, who presented decreased HF, SDNN, and RMSSD in P2. It therefore seems that controlling the training so as to achieve the highest possible parameters reflecting vagus nerve activity is not the sole condition for improving power output at submaximal heart rate.

It would be reasonable to indicate the variables that could serve to predict the effects of training intensification on HRV parameters in a situation where P2 was associated with an increase in vagus nerve activity in three cyclists and no relationship, or an opposite one, was observed in the remaining cases. The potential to make such predictions seems valuable for coaches and athletes in the context of studies that found a relationship between HRV parameters that identify vagus nerve activity and the ability of athletes to perform intense physical effort [20,35]. An attempt to predict the impact of training on HRV was made by Chalencon et al. [44], but their model was based on the observation of a training process implemented earlier. Our intention, in turn, was to try to determine whether it was 
possible to assess the efficacy of training intensification in terms of its impact on HRV on the basis of initial HRV measurements (taken before the training process). Intensifying training is an element of periodisation and constitutes a common practice among endurance athletes during the several weeks preceding important competitions $[2,24,45]$. In our research, we applied a training intensification similar to the classic model. This concept assumes that a period of predominantly L-MIT trainings is followed by a period with a decreasing proportion of L-MIT and a simultaneous increasing proportion of HIT [2]. Our findings (Table 5) imply that baseline HRV (HF, LF, RMSSD, and SDNN) can be a factor that determines the strength and direction of the relationship between $\mathrm{HIT}_{\mathrm{av}}$ and $\mathrm{HRV}$ variables $\left(\mathrm{HF}_{\mathrm{av}}, \mathrm{RMSSD}_{\mathrm{av}}\right.$, and $\left.\mathrm{SDNN}_{\mathrm{av}}\right)$. This information supplements our previous research in which we proved that the effects of periods of training intensification through the use of HIT and sprint interval training could be predicted by an analysis of the training volume in a previous training process $[28,29]$, as well as peak pulmonary minute ventilation in incremental tests and the restitution RMSSD value after a moderate-intensity warm-up [28].

\section{Conclusions}

The presented study results indicate that changes in resting HRV parameters between a period of L-MIT training predominance and a period of increased HIT training proportion can be individualised. Daily records of resting HRV and training loads can allow one to determine whether an increase in high-intensity loads affects changes in HRV parameters in individual cases. In the investigated group, it was possible to predict how HRV would change as a result of training intensification on the basis of the baseline values of HRV parameters, such as HF, LF, RMSSD, and SDNN. Their increase was observed in cyclists with low baseline values of these parameters, and their decrease was found in the cyclist with high baseline values. It also seems that training intensification can also lead to power output improvement at a submaximal heart rate in individuals other than those with an increase in parameters reflecting parasympathetic nervous system activation.

Author Contributions: Conceptualization, P.H. and R.H.; methodology, P.H.; investigation, all authors; data curation, all authors; writing-original draft preparation, P.H. and A.J.; writingreview and editing, R.H. and P.H.; supervision, A.J.; funding acquisition, all authors. All authors have read and agreed to the published version of the manuscript.

Funding: This work was supported by the University School of Physical Education in Wroclaw under grant number PN/BK/2020/07.

Institutional Review Board Statement: The study was conducted according to the guidelines of the Declaration of Helsinki, and approved by Ethics Committee of the University School of Physical Education in Wroclaw (protocol code: 39/2019; date of approval: 26 November 2019).

Informed Consent Statement: Informed consent was obtained from all subjects involved in the study.

Data Availability Statement: Not applicable.

Conflicts of Interest: The authors declare that they have no conflict of interest.

\section{References}

1. Seiler, S. What is best practice for training intensity and duration distribution in endurance athletes? Int. J. Sports Physiol. Perform. 2010, 5, 276-291. [CrossRef] [PubMed]

2. Solli, G.S.; Tønnessen, E.; Sandbakk, Ø. Block vs. traditional periodization of HIT: Two different paths to success for the world's best cross-country skier. Front. Physiol. 2019, 10, 375. [CrossRef] [PubMed]

3. Smith, D.J. A framework for understanding the training process leading to elite performance. Sports Med. 2003, 33, 1103-1126. [CrossRef] [PubMed]

4. Hebisz, P.; Hebisz, R.; Zatoń, M.; Ochmann, B.; Mielnik, N. Concomitant application of sprint and high-intensity interval training on maximal oxygen uptake and work output in well-trained cyclists. Eur. J. Appl. Physiol. 2016, 116, 1495-1502. [CrossRef] [PubMed]

5. Buchheit, M.; Laursen, P.B. High-intensity interval training, solutions to the programming puzzle. Part 1: Cardiopulmonary emphasis. Sports Med. 2013, 43, 313-338. [CrossRef] 
6. Tschakert, G.; Hofmann, P. High-intensity intermittent exercise: Methodological and physiological aspects. Int. J. Sports Physiol. Perform. 2013, 8, 600-610. [CrossRef]

7. Warr-di Piero, D.; Valverde-Esteve, T.; Redondo-Castán, J.C.; Pablos-Abella, C.; Sánchez-Alarcos Díaz-Pintado, J.V. Effects of work-interval duration and sport specificity on blood lactate concentration, heart rate and perceptual responses during high intensity interval training. PLoS ONE 2018, 13, e0200690. [CrossRef] [PubMed]

8. Stöggl, T.; Sperlich, B. Polarized training has greater impact on key endurance variables than threshold, high intensity, or high volume training. Front. Physiol. 2014, 5, 33. [CrossRef]

9. Levine, B.D. $\mathrm{VO}_{2}$ max: What do we know, and what do we still need to know? J. Physiol. 2008, 586, 25-34. [CrossRef]

10. Evertsen, F.; Medbo, J.I.; Jebens, E.; Nicolaysen, K. Hard training for 5 mo increases $\mathrm{Na}(+)-\mathrm{K}+$ pump concentration in skeletal muscle of cross-country skiers. Am. J. Physiol. 1997, 272, R1417-R1424. [CrossRef]

11. Gaskill, S.E.; Serfass, R.C.; Bacharach, D.W.; Kelly, J.M. Responses to training in cross-country skiers. Med. Sci. Sports Exerc. 1999, 31, 1211-1217. [CrossRef]

12. Da Silva, D.F.; Bianchini, J.A.; Antonini, V.D.; Hermoso, D.A.; Lopera, C.A.; Pagan, B.G.; McNeil, J.; Nardo Junior, N. Parasympathetic cardiac activity is associated with cardiorespiratory fitness in overweight and obese adolescents. Pediatr. Cardiol. 2014, 35, 684-690. [CrossRef] [PubMed]

13. Grant, C.C.; Murray, C.; Janse van Rensburg, D.C.; Fletcher, L. A comparison between heart rate and heart rate variability as indicators of cardiac health and fitness. Front. Physiol. 2013, 4, 337. [CrossRef] [PubMed]

14. Ueno, L.M.; Hamada, T.; Moritani, T. Cardiac autonomic nervous activities and cardiorespiratory fitness in older men. J. Gerontol. Ser. A Biol. Sci. Med. Sci. 2002, 57, M605-M610. [CrossRef]

15. Daanen, H.A.; Lamberts, R.P.; Kallen, V.L.; Jin, A.; Van Meeteren, N.L. A systematic review on heart-rate recovery to monitor changes in training status in athletes. Int. J. Sports Physiol. Perform. 2012, 7, 251-260. [CrossRef] [PubMed]

16. Kaikkonen, P.; Hynynen, E.; Mann, T.; Rusko, H.; Nummela, A. Heart rate variability is related to training load variables in interval running exercises. Eur. J. Appl. Physiol. 2012, 112, 829-838. [CrossRef]

17. Schmitt, L.; Regnard, J.; Desmarets, M.; Mauny, F.; Mourot, L.; Fouillot, J.P.; Coulmy, N.; Millet, G. Fatigue shifts and scatters heart rate variability in elite endurance athletes. PLOS ONE 2013, 8, e71588. [CrossRef]

18. Earnest, C.P.; Jurca, R.; Church, T.S.; Chicharro, J.L.; Hoyos, J.; Lucia, A. Relation between physical exertion and heart rate variability characteristics in professional cyclists during Tour of Spain. Br. J. Sports Med. 2004, 38, 568-575. [CrossRef]

19. Pichot, V.; Busso, T.; Roche, F.; Garet, M.; Costes, F.; Duverney, D.; Lacour, J.R.; Barthélémy, J.C. Autonomic adaptations to intensive and overload training periods: A laboratory study. Med. Sci. Sports Exerc. 2002, 34, 1660-1666. [CrossRef]

20. Oliveira, R.S.; Leicht, A.S.; Bishop, D.; Barbero-Álvarez, J.C.; Nakamura, F.Y. Seasonal changes in physical performance and heart rate variability in high level futsal players. Int. J. Sports Med. 2013, 34, 424-430. [CrossRef]

21. Botek, M.; McKune, A.J.; Krejci, J.; Stejskal, P.; Gaba, A. Change in performance in response to training load adjustment based on autonomic activity. Int. J. Sports Med. 2014, 35, 482-488. [CrossRef] [PubMed]

22. Høydal, K.L. Effects of exercise intensity on VO2max in studies comparing two or more exercise intensities: A meta-analysis. Sport Sci. Health 2017, 13, 239-252. [CrossRef]

23. Garber, C.E.; Blissmer, B.; Deschenes, M.R.; Franklin, B.A.; Lamonte, M.J.; Lee, I.; Nieman, D.C.; Swain, D.P. American College of Sports Medicine position stand. Quantity and quality of exercise for developing and maintaining cardiorespiratory, musculoskeletal, and neuromotor fitness in apparently healthy adults: Guidance for prescribing exercise. Med. Sci. Sports Exerc. 2011, 43, 1334-1359. [CrossRef] [PubMed]

24. Issurin, V.B. Biological background of block periodized endurance training: A review. Sports Med. 2019, 49, 31-39. [CrossRef] [PubMed]

25. Figueira, T.R.; Caputo, F.; Machado, C.E.; Denadai, B.S. Aerobic Fitness Level Typical of Elite Athletes is not Associated With Even Faster VO2 Kinetics During Cycling Exercise. J. Sports Sci. Med. 2008, 7, 132-138. [PubMed]

26. Joyner, M.J.; Coyle, E.F. Endurance exercise performance: The physiology of champions. J. Physiol. 2008, 586, 35-44. [CrossRef] [PubMed]

27. Kiely, J. Periodization Paradigms in the 21st Century: Evidence-Led or Tradition-Driven? Int. J. Sports Physiol. Perform. 2012, 7 , 242-250. [CrossRef]

28. Hebisz, R.; Hebisz, P.; Danek, N.; Michalik, K.; Zatoń, M. Predicting changes in maximal oxygen uptake in response to polarized training (sprint interval training, high-intensity interval training, and endurance training) in mountain bike cyclists. J. Strength Cond. Res. 2020. ahead of print. [CrossRef]

29. Hebisz, R.; Hebisz, P.; Borkowski, J.; Zatoń, M. Effects of concomitant high-intensity interval training and sprint interval training on exercise capacity and response to exercise- induced muscle damage in mountain bike cyclists with different training backgrounds. Isokinet. Exerc. Sci. 2019, 27, 21-29. [CrossRef]

30. Beltz, N.M.; Gibson, A.L.; Janot, J.M.; Kravitz, L.; Mermier, C.M.; Dalleck, L.C. Graded exercise testing protocols for the determination of VO2max: Historical perspectives, progress, and future considerations. J. Sports Med. 2016, 2016, 3968393. [CrossRef]

31. Beaver, W.L.; Wasserman, K.; Whipp, B.J. A new method for detecting anaerobic threshold by gas exchange. J. Appl. Physiol. 1986, 60, 2020-2027. [CrossRef] [PubMed] 
32. Wright, J.; Walker, T.; Burnet, S.; Jobson, S.A. The Reliability and Validity of the PowerTap P1 Power Pedals Before and After 100 Hours of Use. Int. J. Sports Physiol. Perform. 2019, 14, 855-858. [CrossRef] [PubMed]

33. Boudreaux, B.D.; Hebert, E.P.; Hollander, D.B.; Williams, B.M.; Cormier, C.L.; Naquin, M.R.; Gillan, W.W.; Gusew, E.E.; Kraemer, R.R. Validity of Wearable Activity Monitors during Cycling and Resistance Exercise. Med. Sci. Sports Exerc. 2018, 50, 624-633. [CrossRef] [PubMed]

34. Windt, J. Polar Beat: Train to your heart's content. Br. J. Sports Med. 2016, 50, 441. [CrossRef]

35. Plaza-Florido, A.; Migueles, J.H.; Mora-Gonzalez, J.; Molina-Garcia, P.; Rodriguez-Ayllon, M.; Cadenas-Sanchez, C.; EstebanCornejo, I.; Solis-Urra, P.; de Teresa, C.; Gutiérrez, Á.; et al. Heart rate is a better predictor of cardiorespiratory fitness than heart rate variability in overweight/obese children: The ActiveBrains project. Front. Physiol. 2019, 10, 510. [CrossRef] [PubMed]

36. Bellenger, C.R.; Fuller, J.T.; Thomson, R.L.; Davison, K.; Robertson, E.Y.; Buckley, J.D. Monitoring athletic training status through autonomic heart rate regulation: A systematic review and meta-analysis. Sports Med. 2016, 46, 1461-1486. [CrossRef]

37. Sandercock, G.R.; Bromley, P.D.; Brodie, D.A. Effects of exercise on heart rate variability: Inferences from meta-analysis. Med. Sci. Sports Exerc. 2005, 37, 433-439. [CrossRef] [PubMed]

38. Macor, F.; Fagard, R.; Amery, A. Power spectral analysis of RR interval and blood pressure short-term variability at rest and during dynamic exercise: Comparison between cyclists and controls. Int. J. Sports Med. 1996, 17, 175-181. [CrossRef]

39. Pichot, V.; Roche, F.; Gaspoz, J.M.; Enjolras, F.; Antoniadis, A.; Minini, P.; Costes, F.; Busso, T.; Lacour, J.R.; Barthélémy, J.C. Relation between heart rate variability and training load in middle-distance runners. Med. Sci. Sports Exerc. 2000, 32, 1729-1736. [CrossRef]

40. Schneider, C.; Wiewelhove, T.; Raeder, C.; Flatt, A.A.; Hoos, O.; Hottenrott, L.; Schumbera, O.; Kellmann, M.; Meyer, T.; Pfeiffer, M.; et al. Heart rate variability monitoring during strength and high-intensity interval training overload microcycles. Front. Physiol. 2019, 10, 582. [CrossRef]

41. Daniłowicz-Szymanowicz, L.; Figura-Chmielewska, M.; Raczak, A.; Szwoch, M.; Ratkowski, W. The assessment of influence of long-term exercise training on autonomic nervous system activity in young athletes preparing for competitions. Pol. Merkur. Lek. 2011, 30, 19-25.

42. Raczak, G.; Daniłowicz-Szymanowicz, L.; Kobuszewska-Chwirot, M.; Ratkowski, W.; Figura-Chmielewska, M.; Szwoch, M. Long-term exercise training improves autonomic nervous system profile in professional runners. Kardiol. Pol. 2006, 64, 135-140.

43. Lamberts, R.P.; Swart, J.; Noakes, T.D.; Lambert, M.I. A novel submaximal cycle test to monitor fatigue and predict cycling performance. Br. J. Sports Med. 2011, 45, 797-804. [CrossRef] [PubMed]

44. Chalencon, S.; Pichot, V.; Roche, F.; Lacour, J.R.; Garet, M.; Connes, P.; Barthélémy, J.C.; Busso, T. Modeling of performance and ANS activity for predicting future responses to training. Eur. J. Appl. Physiol. 2015, 115, 589-596. [CrossRef] [PubMed]

45. Da Silva, K.A.; Lopes, J.A.; de Souza, E.G.; Stanganelli, L.C.R. Effect of a training macrocycle on physiological indicators, body composition, and explosiveness among recreational runners. Hum. Mov. 2020, 21, 49-56. [CrossRef] 